\title{
DETERMINING AND MONITORING THE WATER QUALITY OF KIZILIRMAK RIVER OF TURKEY: FIRST RESULTS
}

\author{
Ö. Gürsoy ${ }^{a *}$, A. C. Birdal ${ }^{\mathrm{a}}$, F. Özyonar ${ }^{\mathrm{b}}$, E. Kasaka ${ }^{\mathrm{c}}$ \\ ${ }^{a}$ Cumhuriyet University, Faculty of Engineering, Department of Geomatics Engineering, 58140 Sivas, Turkey - \\ ondergursoy@gmail.com*, anilcanbirdal@hotmail \\ ${ }^{\mathrm{b}}$ Cumhuriyet University, Faculty of Engineering, Deparment of Environmental Engineering, 58140 Sivas, Turkey - \\ fozyonar@cumhuriyet.edu.tr \\ ${ }^{c}$ Cumhuriyet University, Faculty of Sciences, Department of Biology, 58140 Sivas, Turkey - \\ ekasaka@cumhuriyet.edu.tr
}

KEY WORDS: Water Resources Management, Hyperspectral Imaging, CHRIS Proba, Spectroradiometric Ground Measurements, Water Quality Assessment, Kizilirmak River

\begin{abstract}
:
Water resources are getting more and more important with each passing day in case of survival of humanity. For this reason, assessing water resources' quality and also monitoring them have attracted lots of attention in the recent years. Remote sensing has been growing widely in the last decade and its resources are very usable when it comes to water resources management. In this study, by using remote sensing technology, satellite images that have 350 to 1050 nanometres wavelength band sensors (e.g. CHRIS Proba) are used to determine the quality of the Kizilirmak River's water. Kizilirmak River is born and also pours out to sea in country limits of Turkey. It is the longest river of the country by the length of 1355 kilometres. Through the river's resources, ground based spectral measurements are made to identify the quality differences of the water at the test spots that have been determined before. In this context at Imranli, where the river contacts civilization for the first time, which is located in Sivas city of Turkey, samples are gathered in order to do ground based spectroradiometer measurements. These samples are gathered simultaneously with the image acquiring time of CHRIS Proba satellite. Spectral signatures that are obtained from ground measurements are used as reference data in order to classify CHRIS Proba satellite's hyperspectral images over the study area. Satellite images are classified based on Chemical Oxygen Demand (COD), Turbidity and Electrical Conductivity (EC) attributes. As a result, interpretations obtained from classified CHRIS Proba satellite hyperspectral images of the study area are presented.
\end{abstract}

\section{INTRODUCTION}

Remote sensing techniques provide fast and realiable information about the water quality variables which includes the hydro-physical, biological and biochemical attributes (Chawira et al., 2013, Kutser et al., 2012, Koponen, 2006). By using satellite based imagery, water surface reflectance is measured from a water resource in order to obtain attributes like chlorophyll-a (CHL_A), chemical oxygen demand (COD), Turbidity etc. Remote sensing of water quality started in 1978 when Coastal Zone Colour Scanner (CZCS) sensor was launched in 1978. The spatial resolution of CZCS was not suitable for monitoring small and moderately sized water resources. Through advancing years the spatial resolutions of other satellite sensors like Sea-Viewing Wide Field-of-view Sensor (SeaWiFS), Moderate Resolution Imaging Spectroradiometer (MODIS) or Medium Resolution Imaging Spectrometer (MERIS) are improved in order to work on small study areas (Chawira et al., 2013, Robert et al., 2004). In this study, by using remote sensing technology, satellite images that have 350 to 1050 nanometres wavelength band sensors (e.g. CHRIS Proba) are used to determine the quality of the
Kizilirmak River's water. Through the river's resources, ground based spectral measurements are made to identify the quality differences of the water at the test spots that have been determined before. In this context at Imranli, where the river contacts civilization for the first time, which is located in Sivas city of Turkey, samples are gathered in order to do ground based spectroradiometer measurements. These samples are gathered simultaneously with the image acquiring time of CHRIS Proba. Spectral signatures that are obtained from ground measurements are used as reference data in order to classify CHRIS Proba's hyperspectral images over the study area. Satellite images are classified based on Chemical Oxygen Demand (COD), Turbidity and Electrical Conductivity attributes.

\subsection{Study Area}

Kizilirmak River is born and also pours out to sea in country limits of Turkey. It is the longest river of the country by the length of 1355 kilometers. The study area consists one town named Imranli, which is located in Sivas city of Turkey (Fig. 1).

\footnotetext{
* Corresponding author.
} 


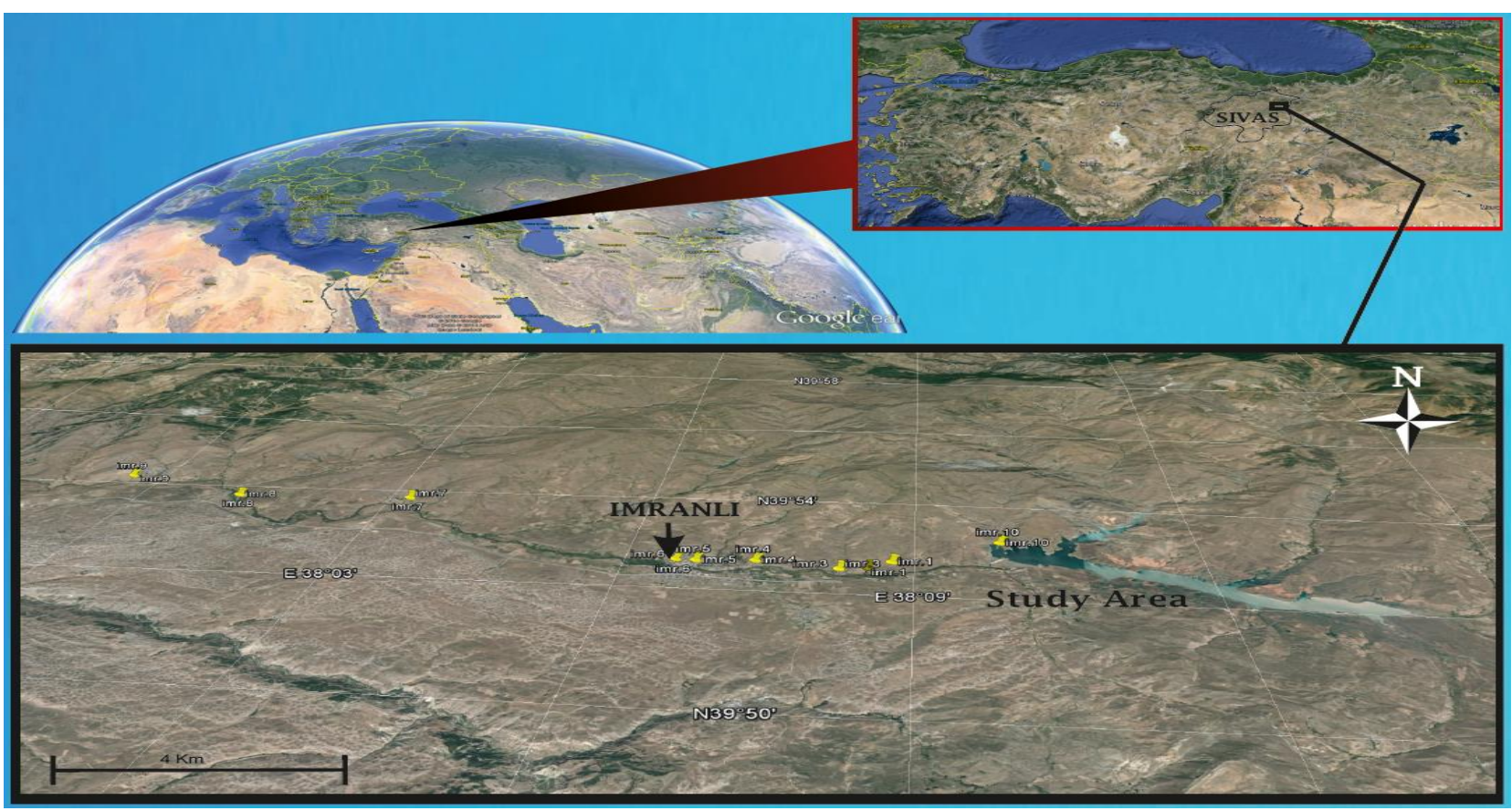

Figure 1. Study area (Yellow markers indicate locations where the water samples are taken)

This town is the first place where the river meets civilization after it is born in Kizildag town of Sivas. The study also consists Imranli Dam which is fed by Kizilirmak river's streams throughout the region.

\section{MATERIALS AND METHODS}

\subsection{Materials}

Field work is specified on gathering the water samples in the study area that were decided beforehand. FieldSpec 4 Spectroradiometer was used to obtain the spectras from the water samples. These spectras have been organized in ViewSpecPRO software provided by ASD Inc (Fig. 2).

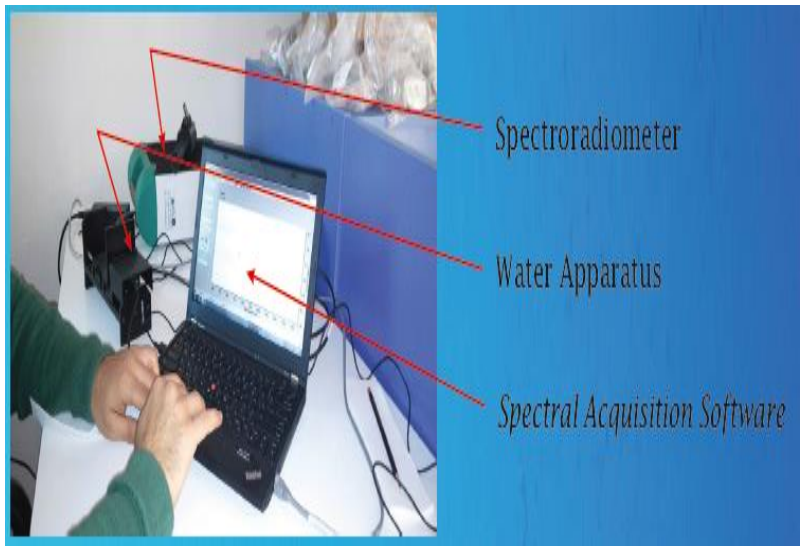

Figure 2. Obtaining the spectras from the water samples
CHRIS Proba images (CHRIS_IM_140830_OC61_41), which has 18 bands (Table 1 ) and $17 \mathrm{~m}$ nadir ground sampling distance, were corrected in atmospheric and radiometric level in BeamVISAT software (Fig. 3). These images then have been georeferenced, layer stacked and then clipped to the region of interest by the shape files provided by General Directorate of State Hydraulic Works of Turkey in order to reduce the image size and make it easy to interpret on them.

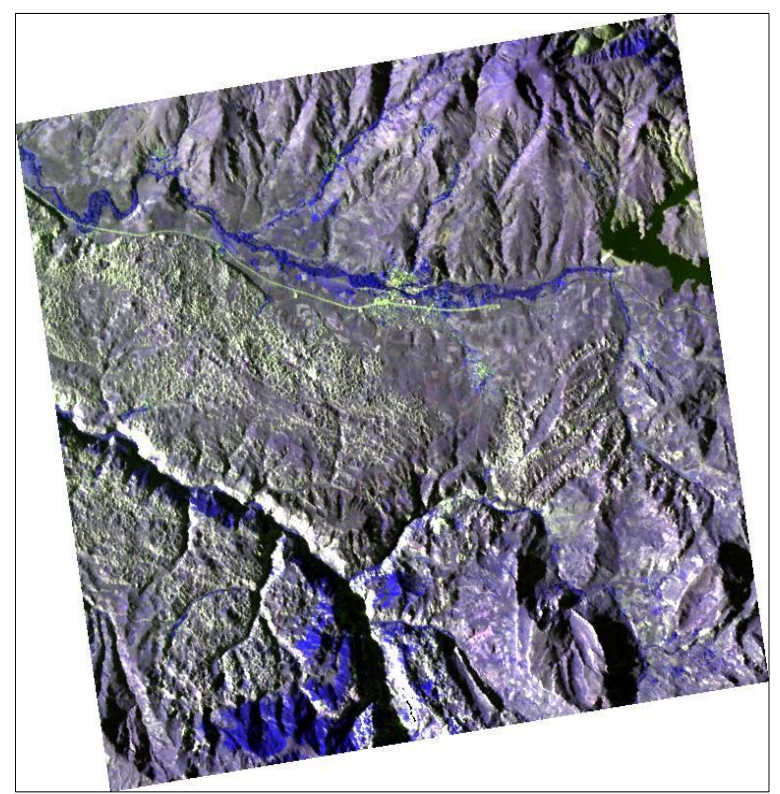

Figure 3. CHRIS Proba image of the study area (R: Band 9, G: Band 4, B: Band 15) 


\begin{tabular}{|c|c|}
\hline CHRIS Proba Bands & Central Wavelength(nm) \\
\hline Radiance_1 & 411.5 \\
\hline Radiance_2 & 443.8 \\
\hline Radiance_3 & 492.1 \\
\hline Radiance_4 & 511.8 \\
\hline Radiance_5 & 532.3 \\
\hline Radiance_6 & 564.0 \\
\hline Radiance_7 & 576.5 \\
\hline Radiance_8 & 593.7 \\
\hline Radiance_9 & 625.8 \\
\hline Radiance_10 & 655.0 \\
\hline Radiance_11 & 673.5 \\
\hline Radiance_12 & 684.7 \\
\hline Radiance_13 & 693.3 \\
\hline Radiance_14 & 711.3 \\
\hline Radiance_15 & 761.3 \\
\hline Radiance_16 & 787.0 \\
\hline Radiance_17 & 879.7 \\
\hline Radiance_18 & 1028.0 \\
\hline Tabl.Specta Wavenght & \\
\hline
\end{tabular}

Table 1. Spectral Wavelenghts of Proba Sensor

\subsection{Water Quality Assessment}

Water samples are evaluated on the basis of water quality class of Turkish Directive on Water Pollution Control. This basis consists of four water quality classes that are lining up from I to IV, making IV. Quality class the dirtiest and the I. Quality is the cleanest water resource (URL 1).

In terms of COD, 1,2,3,4,6,7,9 and 10 water samples in the sample points was found to be I. Water Quality Class, 5 and 8 samples was quality in the II. Water Quality class. There are also some variations amongst other physical parameters EC and turbidity. EC is a parameter based on how much the water can conduct electricity through and signifies substances dissolved in water. When the sample gathering points are analyzed at $1,2,3,4,5,6,7,8$ and $9^{\text {th }}$ points (except $10^{\text {th }}$ which is located at Imranli Dam) EC attributes are increasing according to the flow direction of the river. This might be caused because of the dissolution of rocks where the dam water flows through or the discharge from the settlements nearby. At gathering point 10 (where the dam resides) EC parameter is $371 \mu \mathrm{s} / \mathrm{cm}$ whereas at $9^{\text {th }}$ point the parameter increases to $535 \mu \mathrm{s} / \mathrm{cm}$.

In case of Turbidity the variation between the points are similar to EC. The highest turbidity value is $26,5 \mathrm{NTU}$ which is obtained from $9^{\text {th }}$ point. Turbidity values in the 1.82-26.5 NTU range were measured. For Electrical Conductivity, the range of 399- $535 \mu \mathrm{s} / \mathrm{cm}$ were gathered (Table 2).

\begin{tabular}{|c|c|c|c|}
\hline Locations & $\begin{array}{c}\text { Chemical } \\
\text { Oxygen } \\
\text { Demand }\end{array}$ & $\begin{array}{c}\text { Electrical } \\
\text { Conductivity } \\
(\mu \mathrm{s} / \mathrm{cm})\end{array}$ & $\begin{array}{c}\text { Turbidity } \\
(\mathrm{NTU})\end{array}$ \\
\hline 1 & 10 & 423 & 1,82 \\
\hline 3 & 17 & 430 & 1,09 \\
\hline 4 & 8 & 399 & 1,73 \\
\hline 5 & 32 & 419 & 3,07 \\
\hline 6 & 8 & 420 & 1,17 \\
\hline 7 & 6 & 506 & 0,94 \\
\hline 8 & 35 & 530 & 1,16 \\
\hline 9 & 4 & 535 & 26,5 \\
\hline 10 & 19 & 371 & 1,65 \\
\hline
\end{tabular}

Table 2. Attributes of water sample locations

\subsection{Classification of the Images}

Spectras are readied for Spectral Information Divergence (SID) method. SID method is a spectral classification/mapping method that uses a divergence measure to match pixels to reference spectra. The smaller the divergence, the more likely the pixels are similar. The method uses a threshold attribute. Pixels with a measurement higher than the threshold are not classified. Endmember spectra used by SID method can be uploaded from ASCII files or created spectral libraries, or can be extracted from an image (Fig. 4).

To specify the spectral similarity between two pixels, SID can qualify spectral variability more effectively than the commonly used other spectral classification method Spectral Angle Mapper (Zhang, E., et al., 2014, Chang, C., 2000). SID measures the discrepancy of probabilistic behaviors between the spectral signatures of two pixels from the aspect of information theory, which can be more effective in preserving spectral properties (Zhang, E., et al., 2014). 


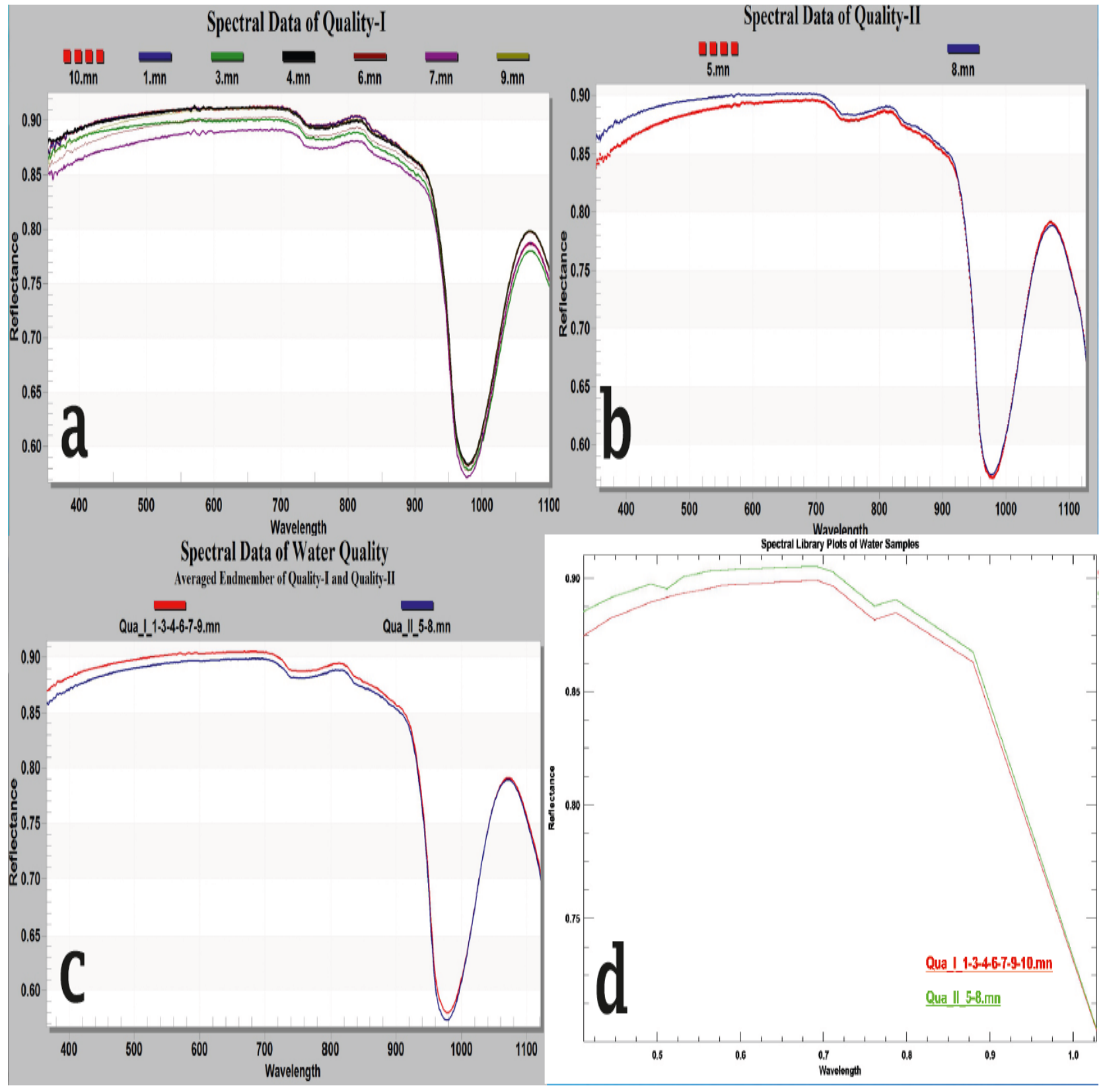

Figure 4. a) Spectral data of Water Quality I, b) Spectral data of Water Quality II, c) Spectral data of both Water Qualities d) Spectral library plot of the both Water Qualities 


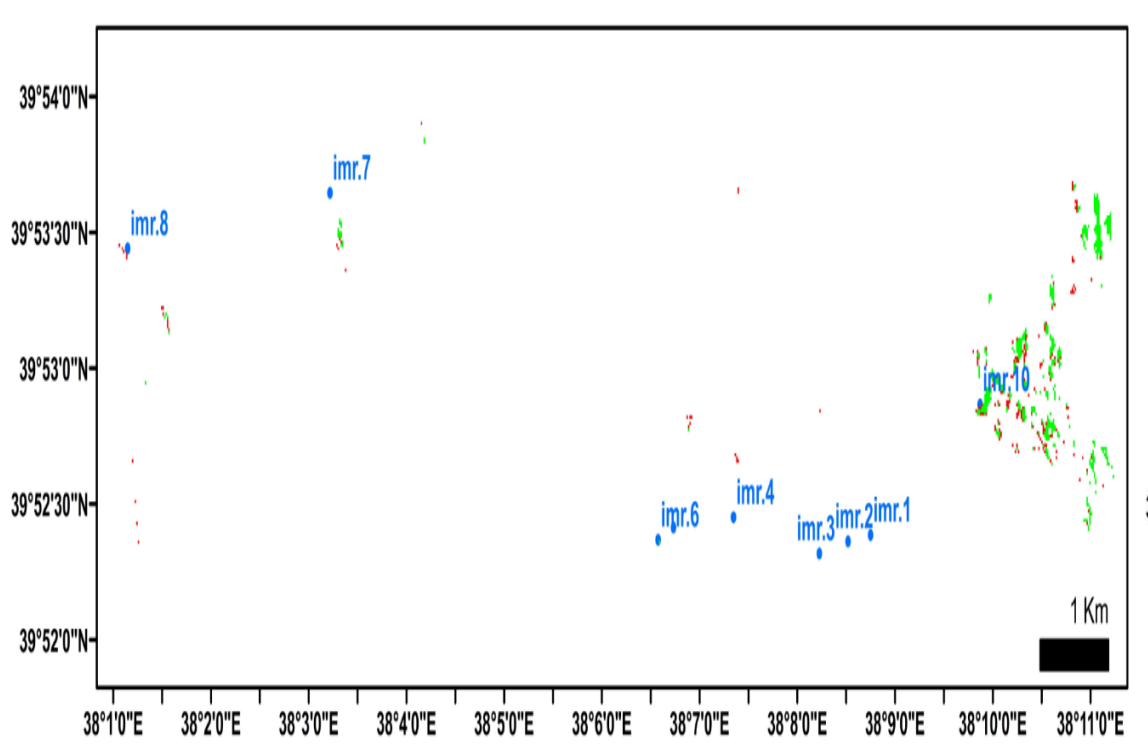

A

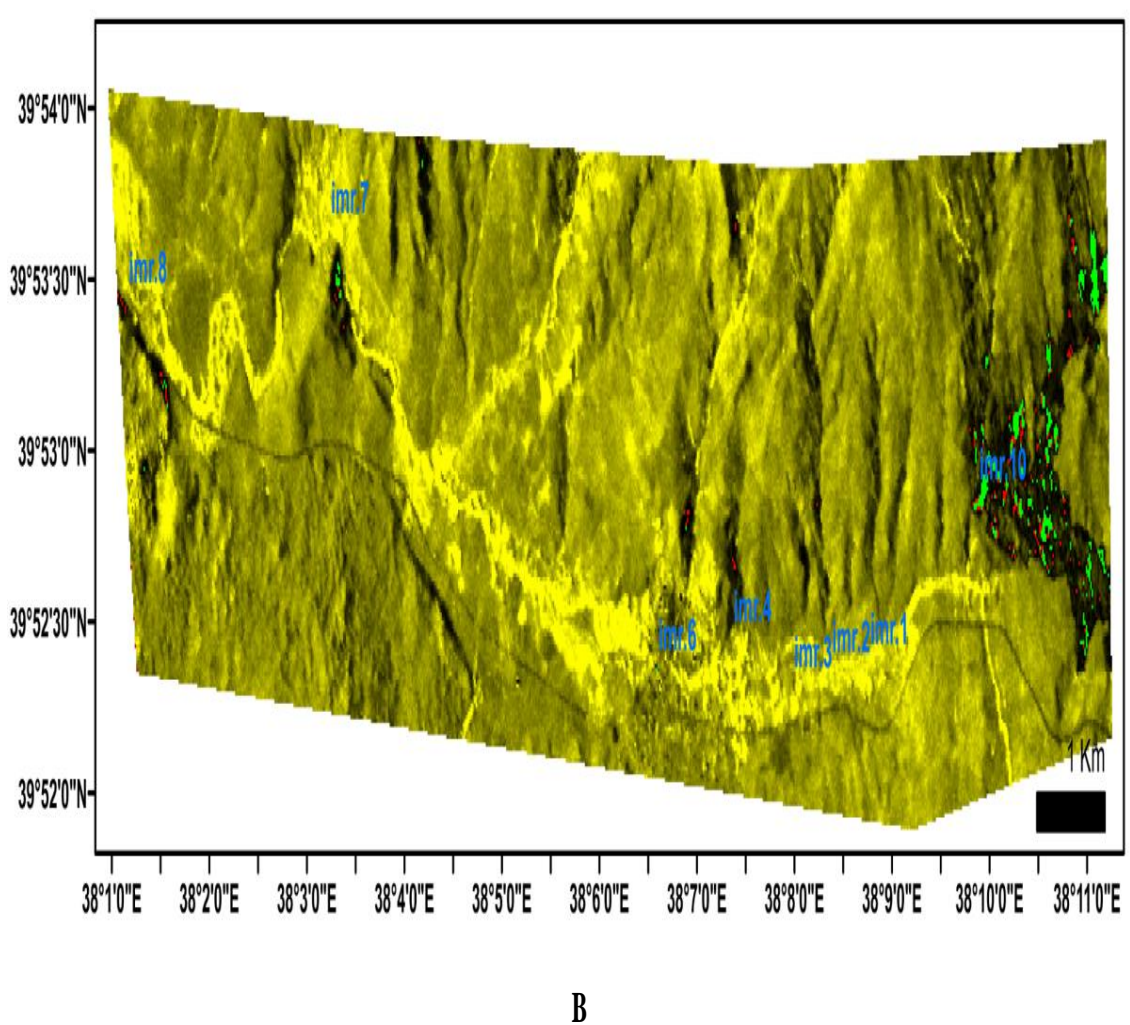

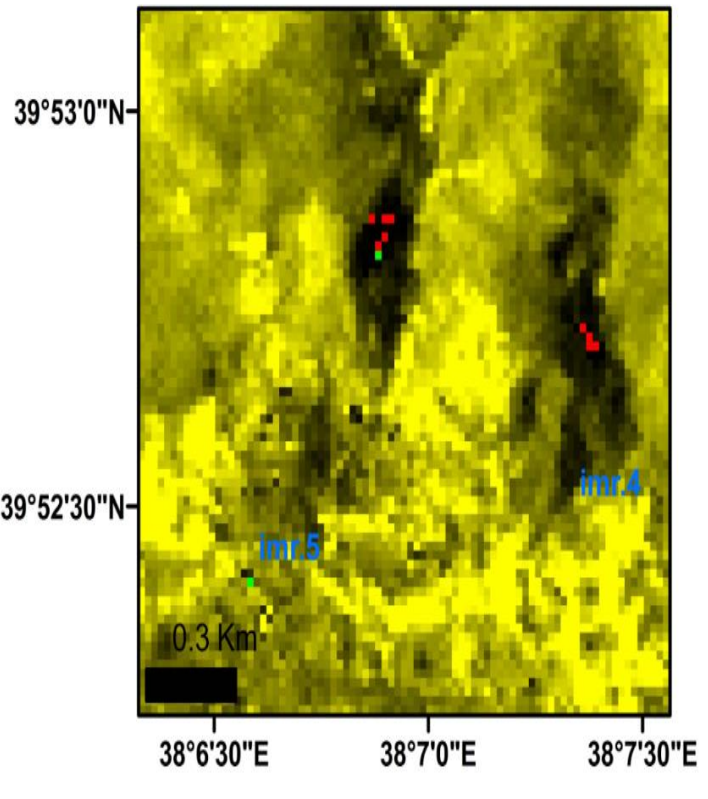

C

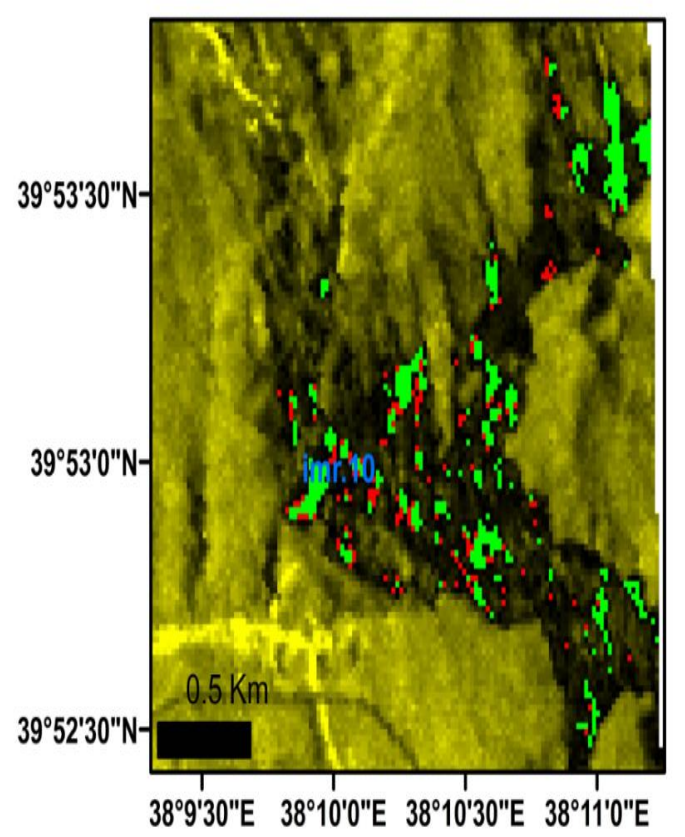

D

Figure 5: a-b) Classifcation of the study area, c) Classification of water resources feeding Imranli town, d) Classification of Imranli Dam (Red pixels are for Quality I, green pixels are for Quliaty II) 


\section{RESULTS}

By interpreting the result classification images (Fig. 5), we can understand that water quality assessment of water bodies can be easily carried out by gathering the water sample spectra with a spectroradiometer and then applying them to high resolution hyperspectral imagery.

In our classified images, only one water body (Imranli Dam) is classified by means of Water Quality I and II. Throughout the river line, the reflectance attributes are not obtained accordingly. Thus the river line couldn't be classified. This might be because, the gathering time of the samples and imagery was at autumn months when the water level is lower than the other months and also might be caused because of the ground pixels that has more details than only the river line.

In our next project high resolution hyperspectral images of the study area will be obtained in order to get better classification results. This method could result in governments taking precautions against water pollutions in order to make their public service better.

\section{ACKNOWLEDGEMENTS}

CUBAP (Cumhuriyet University Scientific Research Projects) is sincerely thanked for their contribution to M-523 numbered project. Also we would like to thank ESA for the acquisition of CHRIS Proba images.

\section{REFERENCES}

Chang Chein-I, "An information-theoretic approach to spectral variability, similarity, and discrimination for hyperspectral image analysis," IEEE Trans. Inf. Theory, vol. 46, no. 5, pp. 1927-1932, Aug. 2000.

Chawira, M., Dube, T., Gumindoga, W., 2013. Remote Sensing Based Water Quality Monitoring in Chivero and Manyame
Lakes of Zimbabwe, Physics and Chemistry of the Earth, Parts A/B/C, Volume 66, 2013, Pages 38-44

Hu, C., Lee, Z., Ma, R., Yu, K.L., Dshang, S., 2010. Moderate Resolution Imaging Spectroradiometer (MODIS) Observations of Cyanobacteria Blooms in Taihu Lake, China. Journal of Geophysical Research 115, 1-22.

Koponen, S., 2006. Remote Sensing of Water Quality: the Development and Use of Water Processors Available in BEAM. Finland, Helsinki: Helsinki University of Technology TKK, Department of Radio Science and Engineering, pp. 1-58.

Kutser, T., Paavel, B.C., Verpoorter, C., Kauer, T., Vahtmae, E., 2012. Remote Sensing of Water Quality in Optically Complex Lakes. International Archieves of the Photogrammetry, Remote Sensing and Spatial, Information Sciences, vol. XXXIX-B8.

Randolph, K., Wilson, J., Tedesco, L., Li, L., Pascual, D.L., Soyeux, E., 2008. Hyperspectral Remote Sensing of Cyanobacteria in Turbid Productive Water Using Optically Active Pigments, Chlorophyll A and Phycocyanin. Remote Sensing of Environment 112 (11), 4009-4019.

Robert, K.V., Xiaoming, Q., Michael, R., McKayb, L., Minerb, J., Czajkowskic, K., Savinod, J., Bridgeman, T., 2004. Phycocyanin Detection from LANDSAT TM Data for Mapping Cyanobacterial Blooms in Lake Erie. Journal: Remote Sensing of Environment 89, 381-392.

Zhang, E., Zhang, X., Yang, S., Wang, S., 2013. Improving Hyperspectral Image Classification Using Spectral Information Divergence, Geoscience and Remote Sensing Letters, IEEE (Volume:11, Issue:1, 249-253)

URL 1: Republic of Turkey, Ministry of Environment and Urbanization, Laws on Management of Water Pollution, 2004, www.csb.gov.tr/db/cygm/editordosya/YON25687SKKY.docx 